\title{
Interview Decision-Makings by HR Practitioners: Statistical Policy-Capturing of Entry-Level Applicants
}

\author{
Kiyoshi Takahashi $^{1^{*}}$, Norihiko Ogawa ${ }^{2}$, and Daisuke Osato ${ }^{3}$ \\ Ritsumeikan University, Japan ${ }^{1 *}$ \\ Hosei University, Japan² \\ Fukuoka Jo-Gakuin University, Japan ${ }^{3}$
}

\begin{abstract}
This study investigates interview criteria using a policy capturing methodology that can identify unconscious standards in experimental decision-making settings. In this regard, a questionnaire was administered to HR staffs in 80 Japanese companies. The findings were as follows: (1) of four criteria, namely attractive appearance, university ranking, person-organization fit ( $\mathrm{P}-\mathrm{O}$ fit), and communication skills, companies set the highest value on applicants' communication skills; (2) companies consider $\mathrm{P}-\mathrm{O}$ fit and university ranking important and do not consider physical attractiveness important; and (3) interviewers with the authority to make decisions about hiring are more concerned about P-O fit than staff interviewers who lack such authority.
\end{abstract}

Keywords: Human resource management, recruiting and training issues, employment interview, criteria for hiring decision, policy capturing methodology.

\section{Employment Interviews: Review and Hypotheses}

There are diverse methods for screening job candidates, but employment interviews are used most frequently (Dipboye, 1997; Ryan, McFarland, Baron, \& Page, 1999; Rynes, Barber, \& Varma, 2000; Wilk \& Cappeli, 2003). At a conservative estimate, more than $90 \%$ of firms worldwide engage in interviews or face-to-face meetings with job candidates before finalizing hiring decisions. Because of its popularity, this specific screening practice has attracted enormous research effort in the past 100 years. The literature has included a number of comprehensive reviews (e.g., Arvey \& Campion, 1982; Harris, 1989; Huffcutt, 2011; Judge, Higgins, \& Cable, 2000; Macan, 2009; McDaniel, Whetzel, Schmidt, \& Maurer, 1994; Posthuma, Morgeson, \& Campion, 2002; Reilly \& Chao, 1982; Schmitt, 1976; Wiesner \& Cronshaw, 1988) and meta-analyses (e.g., Huffcutt, Roth, \& McDaniel, 1996; Levashina, Harttwell, Morgeson, \& Campion, 2014; Marchese \& Muchinsky, 1993; Roth \& Huffcutt, 2013). Consequently, a significant amount of scientific and 


\section{International Conference on Research in HUMAN RESOURCE MANAGEMENT}

\section{March 7-9, 2019 , London- United Kingdom}

practical knowledge has already accumulated to help us understand the advantages and disadvantages of employment interviews.

Originally, a considerable gap existed between the views of academia and the business world regarding the utility and usefulness of employment interviews for decision-making. Practitioners had great confidence in interviews when making hiring decisions, often stating that it was unthinkable to hire people without interviews. However, researchers showed distrust in employment interviews as a method for measuring applicants' aptitudes and gave warnings about interviews' overuse. Judge et al. (2000) summarized the following seven drawbacks to employment interviews that were traditionally found and agreed upon in academia: 1) low reliability, 2) bias from physical appearance, 3) non-verbal bias, 4) negative checks, 5) the primacy of effect-first impression, 6) the similarity effect, and 7) poor recall of interview information. Consequently, until 1989, the literature drew pessimistic conclusions that cast doubt on the significant use of interviews for screening potential employees of organizations (Moscoso, 2000).

However, a review by Harris (1989) prompted research to be more optimistic. Harris provided a balanced view that sometimes contradicted traditional beliefs among researchers and concluded that the modest validity and reliability of interviews enabled them to be accepted as a proper screening device. Currently, three conclusions support the effectiveness of selection interviews (Moscoso, 2000): 1) considering all types of format (e.g., conventional open-ended, structured, behaviorally structured, and situational interviews), interviews are one of the best predictors of job performance and training proficiency; 2) interviews successfully capture diverse constructs such as general intelligence, personality, motivation, social skills, job-related skills and knowledge, and job experience; and 3) interviews show only small group differences that produce less adverse impact on minorities.

The study of employment interviews includes various themes and subjects. Psychometric properties (e.g., reliability and validity), the effects of interview formats (e.g., unstructured, structured, and situational interviews), cognitive biases (e.g., first impression, stereotyping, confirmatory bias, and negative checkup), and adverse impacts are the main streams of this line of research. To date, many new areas have emerged and advanced our understanding of interview decision processes.

Huffcutt (2011) considered the constructs measured in interview studies and provided a metaanalytic review of the literature. He proposed three groups of constructs that affected the hiring decisions of interviewers: personal/demographic characteristics, job-related elements, and interviewee performance. Personal/demographic characteristics include constructs that have been observed in interviews and yet have been treated as biases because they are related to a job indirectly. 


\title{
International Conference on Research in HUMAN RESOURCE MANAGEMENT
}

\author{
March 7-9, 2019 , London-United Kingdom
}

Among these constructs are physical attractiveness, race, gender, and similarity to interviewers in terms of attitude and background. Job-related elements represent the knowledge, skills, abilities, and other characteristics (KSAOs) that directly contribute to job performance. Interviewee performance covers interpersonal exchange during the interview process. For example, because an interview is, by its nature, a social exchange between interviewers and an interviewee, performance encompasses interpersonal behavior and attributes such as communication and social skills.

Based on this framework, the present study suggests four variables to be used in our field experimentation that aims to examine decision policies in mock interview settings: 1) physical attractiveness as a personal/demographic characteristic, 2) educational background as a jobrelated property of an applicant, 3 ) perceived person-organization fit (P-O fit) as a job-related element, and 4) communication skills as an interview performance variable. We set these four variables as the factors that influence hiring decisions. By so doing, this study investigates interview criteria using a policy capturing methodology that can identify unconscious standards in experimental decision-making settings.

\section{Physical Attractiveness}

Interviewers are expected to judge applicants' qualities against the job-related standards. However, social psychological theories and empirical studies have suggested that people who are attractive in appearance are rated and treated more positively than unattractive ones (Anderson \& Adams, 2008; Langlois et al., 2000). Despite the phrase "appearance is deceptive" used by the storyteller Aesop, people assume that beauty is good. In interview research, following Aesop, physical attractiveness is treated as a bias or distortion that hampers the selection of the right persons to the right positions. However, in reality, attractive applicants tend to receive more job qualifications (Dipboye, Fromkin, \& Wiback, 1975; Quereshi \& Kay, 1986) and more hiring recommendations (Cann, Siegfried, \& Pearce, 1981; Gilmore, Beehr, \& Love, 1986) than those who are less attractive. Research has repeatedly found that job interviewers are influenced by the physical attractiveness of applicants (Burnett \& Motowidlo, 1998; Goldberg \& Cohen, 2004; Huffcutt, Jawahar, \& Mattsson, 2005), even when administering structured interviews (Rynes \& Gerhart, 1990).

In their meta-analysis, Hosoda, Stone-Romero, and Coats (2003) discovered that attractive individuals have an advantage over unattractive individuals with regard to many outcomes, including hiring, suitability, performance evaluation, promotion, and perceived success. The weighted mean effect size is as high as .37; thus, beauty is important in many decisions that involve face-to-face interaction. Interestingly, Hosoda, Stone-Romero, and Coats reported that 


\title{
International Conference on Research in HUMAN RESOURCE MANAGEMENT
}

\author{
March 7-9, 2019 , London-United Kingdom
}

attractiveness is more important for males (mean $d=.40$ ) than for females (mean $d=.43$ ). Thus, the relative importance of attractiveness may be incongruent with the common idea of beauty.

\section{Signaling Effect of Education}

Signaling theory has given a powerful insight into the decision-making mechanisms of hiring (Connelly, Certo, Ireland, \& Reutzel, 2011). Spence's (1973) seminal work formulated the signaling function of education in the labor market. Organizations suffer from information asymmetries and lack important information about the quality of specific candidates, including their abilities, length of service/turnover, and fit to the organization. Thus, organizations use educational backgrounds as the signal of candidates' quality in an attempt to reduce information asymmetries.

In the Japanese practice of recruitment, companies first screen applicants according to their educational backgrounds because of the significant amount of interview work required to choose several candidates from hundreds of applicants (Ogawa \& Osato, 2013). For example, the ranking of universities is regarded as efficient for prescreening. Thus, although Japanese companies take a variety of academic backgrounds into account, they prefer students from universities with high reputations. Further, even though HR practitioners do not specifically apply signaling theory, it is apparent that they take the ranking of universities as a signal of applicants' cognitive abilities.

\section{Person-Organization Fit (P-O fit)}

It is widely acknowledged that job interviews are important occasions at which interviewers can evaluate applicants' fit to organizations. Among diverse methods for collecting information about applicants (e.g., application blanks, aptitude tests, academic records, and job experience), practitioners rely heavily on employment interviews to estimate P-O fit during their communication with applicants.

$\mathrm{P}-\mathrm{O}$ fit is defined as the congruence between an attribute of a person and an attribute of an organization (Judge et al., 2000). It includes two types of compatibility between persons and organizations: actual congruence, which refers to the similarity between applicants' characteristics and organizational characteristics objectively recorded or observed, and perceived congruence, which refers to interviewers' subjective judgments of the similarity between applicants' values and organizational values (Kristof, 1996). Based on the finding that objective P-O fit does not have a strong relationship to subjective P-O fit (Adkins, Russell, \& Werbel, 1994), it is important to distinguish between objective and subjective fit. 


\title{
International Conference on Research in HUMAN RESOURCE MANAGEMENT
}

\author{
March 7-9, 2019 , London-United Kingdom
}

Rynes and Gerhart (1990) examined P-O fit researches in interview settings and found that applicants' personal characteristics (e.g., interpersonal skills, goal orientation, and physical attractiveness), and not their objective qualifications (e.g., grade point average and work experience), influence interviewers' subjective $\mathrm{P}-\mathrm{O}$ fit judgments. Similarly, Bretz, Rynes, and Gerhart (1993) reported that job-related coursework or experience, and generally desirable traits such as articulateness and personal appearance, are most frequently mentioned by college recruiters as the determinants of fit. P-O fit, by definition, means the congruence of values and goals; however, these findings consistently indicate that the compatibility of values, rather than the compatibility of appearance and attributes, has a weak connection to fit.

The present study investigates interviewers' judgments of subjective fit because of the finding that hiring decisions are influenced more by interviewers' subjective $\mathrm{P}-\mathrm{O}$ fit than objective $\mathrm{P}-\mathrm{O}$ fit (Cable \& Judge, 1997). Moreover, our discussions with more than 20 HR staff identified the critical importance of P-O fit in recruitment activities (Ogawa \& Osato, 2013). HR staff frequently mentioned that in sequential interviews, interviewers often recommend applicants to the next stage when the applicants are able to show a clear understanding of job assignments. Thus, P-O fit is a significant concern in screening interviews, at least with regard to Japanese recruitment of college graduates, who were the assumed candidates in this study (see Method).

\section{Interview Communication}

In interview settings, information is exchanged via oral communication. Although nonverbal factors are relevant in interview processes, the main stream of information collection is through oral conversation. Indeed, the most straightforward element judged in an interview is, undoubtedly, the level of communication (Arvey \& Campion, 1982). Oral communication is defined as the ability to express (and receive) ideas and information clearly, accurately, and convincingly (Huffcutt, Conway, Roth, \& Stone, 2001). Because a standardized test is yet to be developed to measure interpersonal capacities such as social skills and communication proficiency, it is unsurprising that many organizations use interviews for the assessment of these skills. According to the meta-analysis by Huffcutt et al. (2001), oral communication judged in an interview shows relatively low corrected validity (.26) with job performance. This implies that conversation during an interview more often than not captures information unrelated to the job. Thus, performance in a job cannot be predicted based on the information collected in a typical job interview. In sum, the theories and empirical findings reviewed thus far provide the first hypothesis that is examined in the present study. 


\section{International Conference on Research in HUMAN RESOURCE MANAGEMENT}

\section{March 7-9, 2019 , London- United Kingdom}

Hypothesis 1. The attractiveness of an applicant's appearance, university ranking, perceived $\mathrm{P}-\mathrm{O}$ fit, and perceived communication skills exert positive effects on interviewers' willingness to hire the applicant.

In the practice of recruitment in Japan, applicants are requested to take interviews several times in a sequential manner. Even applicants to entry positions are evaluated repeatedly by different levels of interviewers, from rank-and-file workers to executives. In this regard, interviewers in managerial positions have more power and authority with regard to hiring decisions, while lower-level interviewers simply express their preferences and make recommendations for progress to the next level. Our preliminary discussions with HR managers suggested that in the early stages of screening, relatively young interviewers judge candidates based on the willingness to work together as a prospective coworker; at a later stage, HR managers evaluate candidates by considering the job and related assignments as well as the fit to work organization. In other words, HR managers, who have the power to hire, pay greater attention to the compatibility of candidates with internal job assignments and organizational culture. Finally, board members give their approval for employment in the last meeting with selected candidates. This popular practice of sequential interviews prompts the second hypothesis.

Hypothesis 2. Interviewers' authority to select candidates changes the weighting of the standards against which hiring decisions are made. Of four standards, namely attractive appearance, university ranking, perceived P-O fit, and perceived communication skills, interviewers who are in charge of hiring decisions take P-O fit more seriously than those staff who lack hiring authority.

\section{Method}

\section{Participants}

Questionnaires were sent by mail in January 2015 to the personnel departments of 1,593 Japanese companies listed on the first section of the Tokyo Stock Exchange. In the questionnaire, a policy capturing method was adopted in order to make mock hiring decisions on a paper basis. All potential respondents were advised of appropriate ethical considerations.

Of the 1,593 questionnaires that were delivered, 80 were returned (giving a response rate of $5 \%)$. These 80 consisted of 65 male and 15 female company representatives. The average age of the respondents was 40.52 (s.d.=9.64), and the average length of service in their companies was 16.28 years $($ s.d. $=9.61)$. 


\title{
International Conference on Research in HUMAN RESOURCE MANAGEMENT
}

\author{
March 7-9, 2019 , London-United Kingdom
}

Those respondents who had graduated from four-year colleges or graduate schools represented $95 \%$ of the total, and those who belonged to HR departments represented $97.5 \%$. The respondents held various positions: staff members (22.5\%), supervisors (8.8\%), heads of subsections $(12.5 \%)$, section managers $(41.2 \%)$, deputy heads of departments $(8.8 \%)$, heads of departments (5\%), and general managers (1.2\%). Finally, of the 80 respondents, $68.8 \%$ were in charge of the employment of new graduates and had the authority to make final hiring decisions.

\section{Policy Capturing Methodology}

Policy capturing methodology (Karren \& Barringer, 2002) is based on the idea that what people think is not always what they do. Because people are not always conscious of their decisionmaking, it is hard to obtain correct answers from direct questions such as: What is important to you in this specific situation? (Hobson \& Gibson, 1983). Consequently, the policy capturing method tries to discover actual decision-making rules through observed decision-making patterns.

In the present study, respondents were assumed to run employment interviews of 20 minutes with 36 senior college students aged 22 who attended the recruiting seminars of the respondents' companies. The profiles of candidates were manipulated to include four cues: physical (facial) attractiveness, the reputation of their universities, perceived P-O fit, and perceived communication skills. Each of these had two or three levels. Respondents were asked to review each of 36 portfolios containing facial photographs, the ranking of universities, perceived P-O fit, and subjective impressions of candidates' communication skills.

The reputation of universities was manipulated into three levels based on well-known ranking information: first-tier universities, good universities, and mediocre universities. Perceived P-O fit was operationalized into two levels: whether or not the interviewer had a clear understanding of the job and the department assignments for each candidate. Communication skills were presented in three levels: high, average, and low with regard to each candidate's proficiency compared with the other students. Physical attractiveness was categorized in two levels according to the pilot study data collected from 39 students in three universities (20 males and 19 females). In the pilot study, students were asked to look at 46 facial photographs (23 males and 23 females aged 20-24) and mark attractiveness on a 10-point scale. In order to calculate the average attractiveness score, photographs of nine good-looking and nine less attractive males, and the same type and number of photographs for females, were used.

Thus, the portfolios for 36 applicants were developed through a combination of two levels of facial attractiveness, two levels of perceived P-O fit, three levels of university rankings, and three 


\section{International Conference on Research in HUMAN RESOURCE MANAGEMENT}

\section{March 7-9, 2019 , London- United Kingdom}

levels of communication skills $(2 \times 2 \times 3 \times 3=36$ patterns). All 36 profiles were presented at random to all study participants. Examples of the profiles are shown in Figure 1.

Figure 1 Manipulated Applicant Portfolios

The Best Profile

This candidate is a senior, majoring in the liberal arts in a firsttier university such as the University of Tokyo. Compared with the other student applicants, her communication skills are very impressive. Her interviews show a clear understanding of the job assignment and the division assignments that may suit her.

The Worst Profile

This candidate is enrolled as a senior student in the liberal arts department of a mediocre university. His communication skills are judged as fair and are lower than those of the other student applicants; thus, interviewers may have some concerns about his social skills. The result of his interview is less specific; consequently, a job and department assignments may not be found in this organization.

After reviewing each student profile, respondents were asked to grade them on five-point scales according to three items regarding the respondents' willingness to hire the candidates: I would like to recommend this student to apply for formal entry to my company; this student deserves to take a final job interview at my company; I would like to work with this student as my colleague or subordinate.

This procedure required each respondent to provide 108 decisions (36 portfolios $\times 3$ responses), yielding 8,640 experimental decisions ( 80 participants $\times 108$ decisions). Factor analysis of the three items revealed a one-factor solution referred to as the intention to hire. The sum of the three items capturing the intention to hire was used as the dependent variable with a reliability (coefficient alpha) of .89 . As a result, a total of 2,880 responses ( 80 participants $\times 36$ hiring decisions) were used in the policy capturing analysis. 


\title{
International Conference on Research in HUMAN RESOURCE MANAGEMENT
}

\author{
March 7-9, 2019 , London-United Kingdom
}

In the analysis, the respondents' intentions to hire specific student portfolios were regressed on to the four cues (attractiveness, university ranking, P-O fit, and communication skills). The significance of standardized partial regression coefficients would indicate the importance of unconscious criteria (decision effect) in selection interviews practiced in Japanese companies.

Thus, the intention to hire each new graduate was regressed on to four manipulated factors: attractiveness (2 levels), university ranking (3 levels), P-O fit (2 levels), and communication skills (3 levels). The regression equations included one demographic and two categorical variables in order to control their influence on the decisions: age ( $m=40.52$, s.d.=9.64), management (dummy variable), and authority for employment decisions (dummy variable). The differences in hiring policies between those with and without hiring authority were analyzed by adding interaction variables between the four manipulated factors and the hiring authority dummy. Investigation of these interaction effects would show the policy differences between decision-makers and nondecision-makers.

In addition to these target interaction effects, the regression analysis examined gender differences regarding physical attractiveness. Although the level of attractiveness and gender were contaminated in this policy capturing design, the gender effect of appearance was examined by adding an interaction variable between the female applicants and the level of attractiveness in the equation.

\section{Results}

Table 1 presents the results of regression analysis conducted for the purpose of policy capturing. The results show that three manipulated factors exert significant effects on the intention to hire at the level of .001. Perceived communication skills have the strongest decision effect $(.48, \mathrm{p}<.001)$, followed by perceived $\mathrm{P}-\mathrm{O}$ fit $(.21, \mathrm{p}<.001)$, and university ranking $(.15$, $p<.001)$. Thus, hypothesis 1 is partially supported by the data. However, physical attractiveness has no effect on the hiring decision (.05, n.s.). Contrary to the commonly shared view, the appearance of female applicants has nothing to do with hiring preference among interviewers (.02 , n.s.), indicating that in the current interview context, appearance is not an important factor for the hiring decision, at least when making the decision consciously and carefully. 


\section{International Conference on Research in HUMAN RESOURCE MANAGEMENT}

\section{March 7-9, 2019 , London- United Kingdom}

Table 1 Results of Policy Capturing Regression on to Hiring Intentions

\begin{tabular}{lccc}
\hline & beta & $t$ & $p$ \\
\hline \hline Age & $-.05^{* *}$ & -2.96 & .003 \\
Management (Dummy) & .00 & -.21 & .836 \\
Hiring authority (Dummy) & $-.11^{* *}$ & -2.84 & .004 \\
Attractiveness & .05 & 1.75 & .080 \\
Female $\times$ Attractiveness & -.02 & -.75 & .452 \\
University ranking & $.15^{* * *}$ & 5.49 & .000 \\
P-O fit & $.21^{* * *}$ & 7.67 & .000 \\
Communication & $.48^{* * *}$ & 17.27 & .000 \\
Hiring authority $\times$ Attractiveness & .03 & 1.03 & .304 \\
Hiring authority $\times$ University ranking & .00 & .11 & .912 \\
Hiring authority $\times$ P-O fit & $.12^{* * *}$ & 3.83 & .000 \\
Hiring authority $\times$ Communication & .04 & 1.28 & .200 \\
\hline \multicolumn{1}{c}{$\quad R^{2}$} & .372 & & \\
\multicolumn{1}{c}{$\quad$ Adjusted $R^{2}$} & .369 & & \\
\hline
\end{tabular}

Note: $* * * p<.001, * * p<.01, * p<.05$

With regard to policy investigation, only one interaction effect is significant: The effect of P-O fit $(.12, p<.001)$ is significantly more salient to staff members with decision-making authority than to those without such authority. Comparing the hiring policies between these two groups, employees with decision-making power consider an applicant's fit to an organization more seriously. Decision-makers with the authority to hire are more concerned about the fit between applicants and organizations because they are responsible for the compatibility of candidates and jobs when arranging assignments after hiring. Thus, hypothesis 2 is supported by this result.

In addition, there are interesting tendencies regarding the effects of interviewer characteristics. Older employees give less positive responses for hiring intention $(-.05, p<.01)$ than younger employees when they consider student applicants. Further, staff with decision-making authority for hiring make severer judgments $(-.11, p<.01)$ than occasional interviewers. It is intuitive that older workers and employees with authority view young applicants critically because such interviewers are more deeply committed to their organizations.

\section{Discussion and Conclusion}

The present study conducted a policy capturing analysis with regard to employment interviews. Thus far, little research has been conducted about the policy capturing approach in interview settings. Dougherty, Ebert, and Callender's (1986) study was the exception; however, the authors researched audiotaped interviews and analyzed data collected from only three actual interviewers. Although the present study tried to capture decision-makers' policies in an 


\section{International Conference on Research in HUMAN RESOURCE MANAGEMENT}

\section{March 7-9, 2019 , London- United Kingdom}

experimental situation, it makes a significant contribution because the data were collected from real practitioners in 80 companies. The current stream of interview research focuses on metaanalyses in which all types of interview formats, interviewers, and results are aggregated and collapsed across specific situations to reach generic conclusions. However, individual analyses, rather than aggregated meta-analyses, may provide new and idiosyncratic insights into the interview process (Hammond, Rohrbaugh, Mumpower, \& Adelman, 1977).

This study found that communication skills were the most important determinant for hiring decisions in employment interviews. It is obvious that communication skills are judged in full during a selection interview because of the nature of a face-to-face conversation. Because typical Japanese companies engage in internal job rotation and long-term employment, employees are expected to be committed to firm-specific development and organizational membership, but require no specific job skills as prerequisites of employment. Given the practices of the internal labor market, organizations require job applicants to have high levels of communication proficiency in order to work alongside organizational members and contribute to organizational performance over a long period of time. Thus, communication is an essential element, and is perhaps a more important property than job-specific KSAOs, in organizations that acquire human resources in the internal labor market (Ogawa, Osato, \& Takahashi, 2015).

The most striking finding of this study was the significant policy difference between decisionmakers and occasional interviewers in terms of their approach to P-O fit. People with authority to make hiring decisions are more likely to be concerned about the extent to which potential coworkers fit to the new organization and new job assignments (Ogawa et al., 2015). Practitioners often regard the preliminary compatibility between a person and an organization as the facilitator of a rapid adjustment to a new organizational environment. The present study supports this function of $\mathrm{P}-\mathrm{O}$ fit through its empirical evidence.

Finally, the present study found that the main effect of facial attractiveness was not significant. Together with the subsequent finding of a non-significant interaction effect between female applicants and attractiveness, this study concludes that physical attractiveness is not important with regard to experimental policy capturing in employment interviews. This finding suggests a skeptical view about the effect of facial attractiveness, despite the encouragement given to many student applicants to use special makeup and cosmetics, adopt business-appropriate hairstyles, and commission professional portrait photos. In this regard, further investigation in real interview settings is necessary to provide the educational and business implications of appealing to a wide audience range.

Some limitations may decrease the value of this study. For example, the number of decisionmakers who participated is far from ideal. 


\title{
International Conference on Research in HUMAN RESOURCE MANAGEMENT
}

\author{
March 7-9, 2019 , London-United Kingdom
}

Although the present study collected date from real decision-makers and employees involved in hiring, only 80 persons responded to the mock decision exercises. The low percentage of responses (5\%) may cause selectivity biases that damage the generalization of the study's findings. Remedial action in future research such as a longer period of data collection and a reduction of the response burden in repetitive experimentation will improve the likelihood of cooperation from real business people in such research.

Second, the experimental methodology may cause difficulty for the generalizability of this study. It is widely recognized that experimentation is effective at confirming causal relationships because it can operationalize the function of independent variables. However, this study was not able to benefit from the full advantage of experimentation because it simply utilized paper interviewees for the mock hiring decisions. This may provide results that bear little resemblance to reality. Although a high degree of accuracy for interviewee stimuli can be achieved by using videotaped materials and animations, the present study's researchers had no expertise in movie production. A future study could exploit the advantage given by the current technology of movie production in the process of experimental stimulus construction.

\section{Acknowledgment}

This research was partly supported by JSPS KAKENHI, grant numbers $15 \mathrm{H} 03379$.

\section{References}

Adkins, C. L., Russell, C. J., \&Werbel, J. D. 1994. Judgments of fit in selection processes: The role of work value congruence. Personnel Psychology, 47, 605-623.

Anderson, S. L., \& Adams, G. 2008. The cultural grounding of personal relationship: The importance of attractiveness in everyday life. Journal of Personality and Social Psychology, 95, 352-368.

Arvey, R. D., \& Campion, J. E. 1982. The employment interview: A summary and review of recent research. Personnel Psychology, 35, 281-322

Bretz, R. D., Rynes, S. L., \& Gerhart, B. 1993. Recruiter perceptions of applicant fit: Implications for individual career preparation and job search behavior. Journal of Vocational Behavior, 43, 310-327.

Burnett, J. R., \& Motowidlo, S. J. 1998. Relations between different sources of information in the structured interview. Personnel Psychology, 51, 963-983. 


\section{International Conference on Research in HUMAN RESOURCE MANAGEMENT}

\section{March 7-9, 2019 , London- United Kingdom}

Cable, D. M., \& Judge, T. A. 1997. Interviewers' perceptions of person-organization fit and organizational selection decisions. Journal of Applied Psychology, 82, 546-561.

Cann, A., Siegfried, W. D., \& Pearce, L. 1981. Forced attention to specific applicant qualifications: Impact on physical attractiveness and sex of applicant biases. Personnel Psychology, 34, 6575.

Connelly, B. L., Certo, S. T., Ireland, R. D., \& Reutzel, C. R., 2011. Signaling theory: A review and assessment. Journal of Management, 37, 39-67.

Dipboye, R. L. 1997. Structured selection interviews: Why do they work? Why are they underutilized? In N. Anderson and P. Herriot (Eds.), International Handbook of Selection and Assessment. London: Wiley. (pp. 455-473)

Dipboye, R. L., Fromkin, H. L., \& Wiback, K. 1975. Relative importance of applicant sex, attractiveness, and scholastic standing in evaluation of job applicant resumes. Journal of Applied Psychology, 60, 39-43.

Dougherty, T. W., Ebert, R. J., \& Callender, J. C. 1986. Policy capturing in employment interview. Journal of Applied Psychology, 71, 9-15.

Gilmore, D. C., Beehr, T. A., \& Love, K. G. 1986. Effects of applicant sex, applicant physical attractiveness, type of rater and type of job on interview decisions. Journal of Occupational Psychology, 59, 103-109.

Goldberg, C., \& Cohen, D. J. 2004. Walking the walk and talking the talk: Gender differences in the impact of interviewing skills on applicant assessments. Group and Organization Management, 39, 369-384.

Hammond, K. R., Rohrbaugh, J., Mumpower, J., \& Adelman, L. 1977. Social judgment theory: Applications in policy formation. In M. F. Kaplan, \& S. Schwartz (Eds.), Human Judgment and Decision Processes in Applied Settings. New York: Academic Press. (pp. 171-187)

Harris, M. M. 1989. Reconsidering the employment interview: A review of recent literature and suggestions for future research. Personnel Psychology, 42, 691-726.

Hobson, C. J., \& Gibson, P. W. 1983. Policy capturing as an approach to understanding and improving performance appraisal: A review of the literature. Academy of Management Review, 8, 640-649.

Hosoda, M., Stone-Romero, E., \& Coats, G. 2003. The effects of physical attractiveness on jobrelated outcomes: A meta-analysis of experimental studies. Personnel Psychology, 56, 431462. 


\section{International Conference on Research in HUMAN RESOURCE MANAGEMENT}

\section{March 7-9, 2019 , London- United Kingdom}

Huffcutt, A. I. 2011. An empirical review of the employment interview construct literature. International Journal of Selection and Assessment, 19, 62-81.

Huffcutt, A. I., Conway, J. M., Roth, P. L., \& Stone, N. J. 2001. Identification and meta-analytic assessment of psychological constructs measured in employment interviews. Journal of Applied Psychology, 86, 897-913.

Huffcutt, A. I., Roth, P. L., \& McDaniel, M. A., 1996. A meta-analytic investigation of cognitive ability in employment interview evaluations: Moderating characteristics and implications for incremental validity. Journal of Applied Psychology, 81, 459-473.

Huffcutt, A. I., Jawahar, I. M., \& Mattsson, J. 2005. Sexism and beautyism effects in selection as a function of self-monitoring level of decision maker. Journal of Applied Psychology, 90, 563573.

Judge, T. A., Higgins, C. A., \& Cable, D. M. 2000. The employment interview: A review of recent research and recommendations for future research. Human Resource Management Review, 10, 383-406.

Karren, R. J., \& Barringer, M. W. 2002. A review and analysis of the policy capturing methodology in organizational research: Guidelines for research and practice. Organizational Research Methods, 5, 337-361.

Kristof, A.L. 1996. Person-organization fit: An integrative review of its conceptualizations, measurement, and implications. Personnel Psychology, 49, 1-49.

Langlois, J. H., Kalakanis, L., Rubenstein, A. J., Larson, A., Hallam, M., \& Smoot, M. 2000. Maxims or myths of beauty? A meta-analytic and theoretical review. Psychological Bulletin, 126, 390-423.

Levashina, J., Harttwell, C. J., Morgeson, F. P., \& Campion, M. A. 2014. The structured employment interview: Narrative and quantitative review of the research literature. Personnel Psychology, 67, 241-293.

McDaniel, M. A., Whetzel, D. L., Schmidt, F. L., \& Maurer, S.D. 1994. The validity of employment interviews: A comprehensive review and meta analysis. Journal of Applied Psychology, 79, 599-616.

Macan, T. 2009. The employment interview: A review of current studies and directions for future research. Human Resource Management Review, 19, 203-218.

Marchese, M. C., \& Muchinsky, P. M. 1993. The validity of the employment interview: A metaanalysis. International Journal of Selection and Assessment, 1, 18-26. 


\section{International Conference on Research in HUMAN RESOURCE MANAGEMENT}

\section{March 7-9, 2019 , London- United Kingdom}

Moscoso, S. 2000. Selection interview: A review of validity evidence, adverse impact and applicant reactions. International Journal of Selection and Assessment, 8, 237-247.

Ogawa, N., \& Osato, D. 2013. Report on hiring practices of Japanese companies for new graduates. Research Institute for Innovation Management, working paper series \#140 (in Japanese).

Ogawa, N., Osato, D. \& Takahashi, K. 2015. Criteria for screening job applicants in Japanese companies: Policy capturing approach. Journal of Academy of Business and Economics, 15, 101-109.

Posthuma, R. A., Morgeson, R. P., \& Campion, M. A. 2002. Beyond employment interview validity: A comprehensive narrative review of recent research and trends over time. Personnel Psychology, 55, 1-81.

Quereshi, M. Y., \& Kay, J.P. 1986. Physical attractiveness, age, and sex as determinants of reactions to resumes. Social Behavior and Personality, 14, 103-112.

Reilly, R. R., \& Chao, G. T. 1982. Validity and fairness of some alternative employee selection procedures. Personnel Psychology, 35, 1-62.

Roth, P. L., \& Huffcutt, A. I. 2013. A meta-analysis of interviews and cognitive ability. Journal of Personnel Psychology, 12, 157-169.

Rynes, S. L., Barber, A. E., \& Varma, G. H. 2000. Research on the employment interview: Usefulness for practice and recommendations for future research. In C. L. Cooper and E. A. Locke (Eds.), Industrial and Organizational Psychology. Oxford: Blackwell Business.

Rynes, S. L., \& Gerhart, B. 1990. Interviewer assessments of applicant 'fit': An exploratory investigation. Personnel Psychology, 43, 13-35.

Ryan, A. M., McFarland, L., Baron, H., \& Page, R. 1999. An international look at selection practices: Nation and culture as explanations for variability in practice. Personnel Psychology, 52, 359391.

Schmitt, N. 1976. Social and situational determinants of interview decisions: Implications for the employment interview. Personnel Psychology, 29, 79-101.

Spence, M. 1973. Job market signaling. Quarterly Journal of Economics, 87, 355-374.

Wiesner, W. H., \& Cronshaw, S. F. 1988. The moderating impact of interview format and degree of structure on interview validity. Journal of Occupational Psychology, 61, 275-290.

Wilk, S. L., \& Cappelli, P. 2003. Understanding the determinants of employer use of selection methods. Personnel Psychology, 56, 103-124. 